УДК 159.923

doi: $10.15330 /$ ps.9.1.104-119

Leonid Levit

Center for psychological health and education (Minsk, Belarus)

leolev44@tut.by

\title{
ЗЛО СИЛЬНЕЕ ДОБРА, ЕСЛИ ДОБРО ВАЖНЕЕ ИСТИНЫ: ДОКАЗАТЕЛЬСТВА И СЛЕДСТВИЯ
}

\begin{abstract}
В статье исследуется соотношение трёх главных человеческих иенностей - истины, добра и красоты. Критический анализ известных философских положений проводится с использованием результатов, полученных в современных экспериментальных исследованиях. В частности, обсуждается противоречие между требованием о приоритете истины перед добром в ситуации конфликта между этими ценностями и воздействием позитивных иллюзий, вылвленных современной нейронаукой и свойственных функиионированию человеческого мозга. Так, широко распространен эффект «ложной уникальности», при котором человек переоченивает собственные (точнее, высоко желаемые) позитивные качества и недооченивает негативные. Массовая приверженность индивидов заблуждениям относительно величины своего внутреннего потенииала, наличия глубоко скрытых ресурсов в сочетании со стремлением поддержать высокую самооценку ведут к искажению проводимых сочиальных сравнений. Автор доказывает, что придание добру большей значимости в сравнении с истиной неминуемо ведёт к последующей победе зла над добром. Подобное происходит в связи с большей доступностью и привлекательностью «неистинного» добра перед «истинным». Главное преимущество опоры на истину заключается в её умении распознавать и отделять долговременные разновидности добра от его краткосрочных (как правило, гедонистически ориентированных) вариантов, нередко оборачиваюшихся злом в более отдалённой перспективе. Настоящее (истинное) добро, как правило, требует приложения первоначальных усилий, однако приносит пользу в течение длительного времени и оборачивается другими полезными эффектами. В конце статьи приводятся практические рекомендации, а также личный опыт автора, позволяющие информированному индивиду организовать собственное мылление и поведение с учётом выявленных закономерностей.
\end{abstract}

Ключевые слова: адаптация, добро, зло, истина, позитивные иллюзии, смысл, эгоизм.

Предварительные замечания. Сложность поднимаемой темы (в первую очередь, многообразие трактовок, меняющиеся по ходу статьи масштабы рассмотрения и вариативность проявлений субстанций, обозначаемых терминами «истина», «добро» и «зло»), не позволила нам соблюсти полное «академическое» единообразие в предлагаемом тексте. Очевидно, что истина, добро и зло могут рассматриваться как с точки зрения «объективных» признаков (например, заметных последствий тех или иных выборов человека), так и «субъективных» внутренних состояний. Иногда более-менее подходящим синонимом зла в тексте выступает понятие «негатив», а добра - «позитив». Надеюсь, что соответствующие контексты, а также их изменения будут понятны читателю (иногда с этой целью используются кавычки, иногда заглавные буквы при написании соответствующих слов в середине предложения).

Автор видел свою задачу не в гладком «причёсывании» проблемы взаимодействия истины, добра и зла (о создании очередной классификации всегда есть кому позаботиться), а в максимальном продвижении вперёд с точки зрения содержания и получения важных выводов на стыке философии, современной экспериментальной психологии и других наук, изучающих человека. При таком подходе общепринятые научные термины и выявленные закономерности используются в качестве рабочих инструментов - своего рода дощечек, дающих временную опору при движении по зыбкой местности и не позволяющих утонуть в самом начале пути. Как сказал один из учёных, некоторым понятиям нельзя (по крайней мере, до определённого времени) давать слишком точные дефиниции - в интересах дальнейшего развития науки.

Введение. Уже древние философы выделили три основные, «вечные» ценности - истину, добро и красоту. Их сочетание приводит к жизненной гармонии. В ситуации конфликта, необходимости выбора между тремя ценностями предпочтение следует отдать истине [20]. Иными словами, считается, что для человека и человечества в целом «лучше горькая правда, чем сладкая ложь». В данном философском тезисе, имеющем прямое отношение к вопросу «как 
жить», мы собираемся разобраться с учётом достижений современной экспериментальной психологии и смежных наук.

В повседневной жизни чаще имеет место пренебрежение истиной в пользу добра и красоты. В отличие от добра, следование истине никогда не входит в число праздничных пожеланий. Истина, в отличие от красоты, не становится темой для комплиментов.

Большинство людей стремится получить от жизни добро, разнообразный позитив причём, желательно, как можно скорее. Наиболее рельефно подобная закономерность раскрывается в краткосрочном гедонизме - массовой погоне за простыми и быстрыми удовольствиями [5]. В настоящей статье мы продемонстрируем новые, ранее не замеченные учёными опасности гедонистической (и в целом односторонне-позитивной) ориентации. Особенно приятно сознавать, что полученные «прикладные» выводы подтверждают глобальную идею, столь близкую и понятную настоящему исследователю: истина превыше всего. Сие, в частности, означает, что в ситуации выбора в повседневной жизни информированному, интеллектуально и духовно развитому индивиду следует отдать предпочтение любой «недоброй истине» перед любым «неистинным добром» - причём сделать это ради собственного долговременного благополучия (т. е., в конечном итоге, ради добра). Поскольку процесс принятия, а тем более продуктивного использования «недоброй истины» сложен и кажется неоднозначным, мы приведём в конце статьи личный опыт, а также приёмы мышления, которые должны облегчить первоначальные затруднения.

Добро и позитивные иллюзии. Итак, современный человек нацелен на поиск и получение быстрого и лёгкого добра. Конечным результатом такого поиска должно явиться достижение счастья. Оптимизм и надежда на чудо усиливаются навязчивой рекламой, занимающейся по большей части «продажей мечты» («быстрого неистинного добра» в нашей терминологии) и динамичным темпом современной жизни, при котором благоприятные возможности, «шансы» и «социальные лифты» должны, казалось бы, появляться на каждом шагу.

Также подобная установка подпитывается позитивныли иллюзиями - частично или полностью ложными убеждениями положительного свойства, являющимися, как доказала наука последних десятилетий, свойством человеческого мозга. Как минимум, речь идёт о 80 процентах индивидов в экспериментальных выборках [15].

Кратко назовём основные группы позитивных иллюзий. Результаты социальнопсихологических исследований демонстрируют широко распространенный эффект «ложной уникальности» (false uniqueness), при котором человек переоценивает «собственные» (точнее, высоко желаемые) позитивные качества и недооценивает негативные [19]. Массовая приверженность индивидов заблуждениям относительно своего «неповторимого внутреннего потенциала», наличия «глубоко скрытых ресурсов» в сочетании со стремлением поддержать высокую самооценку ведут к искажению проводимых социальных сравнений.

Темы собственной одарённости и успешной самореализации настолько популярны, что оказывают существенное влияние на специфику статистического распределения по результатам заполнения тестов гуманистической направленности, создавая изрядный процент «псевдосамоактуализаторов» [17]. В свое время автору данной статьи пришлось несколько лет трудиться над разработкой специальных приёмов в собственном диагностическом опроснике «ЭЛУ Плюс», чтобы избавиться в нём от правосторонней асимметрии и эксцесса [8].

Другие позитивные иллюзии индивида основаны на преувеличенной уверенности в своей способности контролировать окружающий мир и нереалистическом оптимизме. Так, исследования демонстрируют веру большинства людей в то, что их будущее окажется лучшим, нежели предположения о нём, имеющие чисто статистическую основу. Даже снабжение испытуемых объективной информацией заставляет их по-прежнему предпочитать излишне позитивные убеждения и действовать на их основе. Иными словами, почти каждый индивид 
упорно и ошибочно считает, что его способности превышают средний уровень, а его самого ждёт «лучшее будущее».

Позитивные иллюзии, отнесённые к уровню социума, заставляют людей верить в возможность построения утопии - идеально устроенного общества, в котором каждый сумеет раскрыть свой «уникальный внутренний потенциал» и добиться счастья. К утопическому взгляду и его сравнению с иным, более адекватным мировоззрением, мы вернёмся ниже.

А что говорит нам «недобрая истина» - проверенные закономерности? Неумолимая реальность свидетельствует о разительном несовпадении желаемого (определяемого позитивными иллюзиями) и действительного в оценке «талантов» и их реализации. По наблюдениям А. Маслоу, успешно актуализируется менее одного процента людей. Даже прекрасные внешние условия, на создание которых возлагают столь большие надежды социальные утописты, крайне редко приводят к индивидуальной самоактуализации [18]. Приходится признать, что для индивидуального успеха требуется как минимум врождённый талант и трудолюбие. Природа несправедлива в распределении своих даров: большинство людей появляется на свет «с пустыми руками», а отнюдь не с уникальным внутренним потенциалом, как нас пытаются уверить романтики и гуманисты.

Долговременное зло на основе кратковременного добра. Позитивные иллюзии людей (желание получить лёгкое и быстрое «счастье») эксплуатируются разнообразными способами и во многих сферах. Так, реклама «возбуждает» гедонистическую ориентацию возможного потребителя, обещая тому «прекрасную жизнь» после приобретения определённого товара или услуги. Целое научное направление - позитивная психология - сосредоточено на поиске всевозможных видов благополучия, создавая глубоко ошибочное представление, будто в жизни возможно чистое счастье, свободное от любых негативных переживаний.

Разумеется, наиболее простой формой «добра», которое можно быстрее всего получить, становятся материалистические, чувственные (ориентированные на органы чувств) потребительские удовольствия. Возможность быстро «взбодриться», «поднять настроение» ценится весьма высоко. В динамичной рыночной цивилизации, сулящей индивиду столь многое (вплоть до искажения объективной действительности со стороны компьютерной дополненной реальности), происходит «резонанс» внутренних (представленных, главным образом, позитивными иллюзиями) и внешних (связанных с развитием всевозможной рекламы и потребительски ориентированных технологий) факторов. «Предвкушение счастья» не только приятно в качестве позитивного переживания [2], но и способствует массовому принятию краткосрочного гедонизма в качестве «продвинутой» жизненной философии.

При этом мало кто думает о поначалу скрытых, однако долговременных, отнюдь не радостных результатах безудержной погони за добром, которые выявлены современной наукой, и, стало быть, представляют собой очередную нерадостную истину. Перечислим основные негативные эффекты, которые обычно идут по нарастающей.

1. Гедонистический парадокс. Нацеленный на получение максимального удовольствия индивид оказывается в психологической ловушке: чем больше он думает о наслаждении, тем меньше его ощущает [14].

2. Быстрое наступление привыкания (адаптаџия). В большинстве простых удовольствий адаптация появляется уже при втором повторении и затем усиливается. Иными словами, каждая новая ложка чёрной икры, каждое новое прослушивание популярной песни ощущаются всё менее остро, доставляют меньше приятных переживаний. «Всё проходит», как было написано на перстне царя Соломона. Эффект привыкания («притупления» приятных ощущений) настолько очевиден, что некоторые учёные считают адаптацию пока единственнылм законом, выявленным современной психологией. Конечно, существуют виды сложной, творческой деятельности, в которых привыкание (скука) практически не возникает [9]. Однако эти занятия требуют предварительного, не всегда приятного обучения, опыта и постоянного 
приложения усилий субъекта, а потому лежат вне пределов краткосрочного гедонизма, противореча самой его идеологии.

3. Формирование зависимости (аддикция). В результате возникающего привыкания индивид вынужден тратить с каждым разом всё больше времени (увеличивать «дозу»), чтобы получить требуемый «кайф». Такое нарастающее повторение создаёт привычку (зависимость), от которой человеку трудно отказаться в дальнейшем, когда проявляются негативные последствия данной активности. Наконец, в какой-то момент ситуация переворачивается: искомое занятие перестаёт приносить удовольствие. Оно становится лишь средством избегания «неудовольствия» («ломки») и тщетных попыток восстановления душевного равновесия и комфорта - состояний, которыми психически здоровый индивид и так обладал до приобщения к дурной привычке. В результате «быстрое» добро обернулось долгим, если не пожизненным, злом.

4. Утрата смысла жизни, остановка в собственном развитии. Гедонизм как самоцель в больших дозах ведет к лени, ощущению бессмысленности и пустоты существования [23]. Например, известно, что просмотр телепередач приносит мало радости, но требует еще меньших усилий, поэтому столь популярен.

5. Избалованность и капризность, потеря способности справляться с обычными жизненными трудностями. Предпочтение лёгкого и быстрого добра «естественным образом» (если это словосочетание уместно в данном случае) отучает от сложных видов деятельности, достижение результата в которых требует усилий и самопреодоления, выхода из зоны комфорта. По контрасту, любое мелкое затруднение, которыми изобилует жизнь, «разрастается в масштабах», драматизируется и вызывает чрезмерные негативные переживания. Возникшая проблемная ситуация не может быть удовлетворительно разрешена субъектом с помощью действий из-за необходимости соприкасаться с «негативом», который теперь ощущается гораздо острее. Из-за адаптации к позитиву его границы сужаются, и наоборот, расширяется область явлений, ныне оцениваемых в качестве отрицательных и «непреодолимых».

6. Возможное расстройство психики (невроз). Индивид, «загнавший себя в угол», практически не оценивает многие виды жизненного позитива в качестве такового из-за адаптации и ошибочной установки, что «так и должно быть». Наоборот, теперь его психика пребывает во власти «зла» (более или менее реального), которое увеличилось в масштабах и острее воспринимается вследствие неадекватных требований к реальности, разросшихся потребностей («мир должен дать мне хорошее или даже самое лучшее, ведь я этого достоин»), веры в существование идеального жизненного устройства, а также идеальных (не содержащих отрицательных сторон) решений. С нашей точки зрения, необоснованные попытки «насильственного» сдвига границ реальности в сторону господства позитива и игнорирования негатива (не всегда приятного, однако имеющего немало полезных функций) привели в последние полвека к десятикратному росту депрессивных и тревожных расстройств [21, с. 43; 369], характеризующихся господством именно отрицательных переживаний. Складывается впечатление, что человечество высекло само себя (принесло себе дополнительное зло в лихорадочной погоне за немедленным добром), и, не замечая случившегося, продолжает делать ошибки: «терпение приносит розы, а нетерпение - неврозы». Превращение многих видов краткосрочного добра в постоянное зло буквально ввергает былого охотника за «райскими наслаждениями» в психологический (и нередко физиологический) «ад».

Единственно возможный способ борьбы с адаптацией заключается в ограничении (делать реже) либо полном воздержании от возникшей привычки [12]. То есть, чтобы уменьшить поступление «зла», человек должен сознательно ограничить контакт с тем, что он считал или продолжает считать «добром»! Если же зло полностью овладело человеком, превратившись в аддикцию, тогда искоренить его поможет другое «зло» - полный отказ от былых удовольствий. Нередко подобное воздержание на первых порах сопровождается «ломкой» - тяжёлым негативным состоянием, которое нужно попросту терпеть. Интересно, 
что после успешно проведённого «карантина» острота удовольствия возвращается к прежнему уровню, после чего (у неустойчивого субъекта, оказавшегося в экзистенциальном вакууме) может начаться новый цикл гедонизма.

Для лучшего понимания и оценки сказанного приведём пример с противоположной последовательностью (условного кратковременного «зла», переходящего в долговременное «добро») - периодические голодания, предпринимаемые человеком с оздоровительной целью. Известно, что воздержание от пищи сопровождается разного рода неприятными ощущениями, включающими в себя временное обострение симптомов имеющихся заболеваний. Однако первые дни выхода из голодания наполняют ощущением силы, бодрости и прекрасного здоровья, продолжительность которого во многом зависит от последующего образа жизни. В данном случае сознательное прохождение индивида через краткосрочное «зло» (отсутствие пищи, обострение симптомов болезни и другие малоприятные состояния) влечёт за собой наступление «добра» (выздоровление или как минимум ремиссию симптомов).

В случае сформировавшейся аддикции долговременное «зло», возникшее на основе краткосрочного «добра», управляет человеком; в примере же с оздоровительным голоданием человек по своей воле подвергает себя кратковременному «злу» ради получения долговременного «добра». Кстати, на биологическом уровне во время голодания «добро» побеждает «зло»: как известно, в первую очередь организм утилизирует в пищу разного рода ненужные ткани, болезненно изменённые клетки и т. д. В то же время наиболее «ценное» (например, клетки головного мозга и нервной системы) остаётся практически нетронутым даже при длительных сроках воздержания от пищи.

Экспериментальные исследования показывают, что к негативу современный человек адаптируется хуже, чем к сопоставимому позитиву. Это, вероятно, происходит и потому, что в соответствии с подогреваемыми позитивными иллюзиями индивид верит в получения от жизни исключительно «добра». Так, выявленное Дж. Готтманом соотношение «пять к одному» говорит о том, что наше негативное впечатление от одного отрицательного поступка, совершённого партнёром по общению, сглаживается не ранее, чем этот же партнёр совершит по отношению к нам как минимум пять сопоставимых положительных поступков [13; 16]. «Не ожидай добра и не получишь зла».

Раздутая тяга к добру и забвению истины проникла даже в гуманитарные науки, оформившись в так называемом «утопическом» взгляде на человека и общество, нередко смешивающем желаемое и действительное, установленные факты (то, что есть) с идеологией и моральными оценками (тем, как должно быть) [22]. Согласно воззрениям представителей утопического подхода, ведущего свою историю от концепции «благородного дикаря» (noble savage) Ж. Ж. Руссо, новорожденный не обладает какими-либо собственническими или «порочными» инстинктами. Поэтому потенциальное совершенство человеческой природы не знает пределов. Отдельно существуют чистое добро и абсолютное зло. Любой индивид способен бесконечно меняться к лучшему в идеально устроенном обществе недалекого будущего. Современный утопизм в науке и социальной жизни Запада нередко выступает под масками антиглобализма, мультикультурализма и феминизма.

Идеи, лежащие в основе противоположного - «трагического» подхода, предполагают неизменность человеческой природы, которая определяется врожденным эгоизмом предрасположенностью индивида в свою пользу, приоритетным вниманием к собственным нуждам. Порождаемые эгоизмом различия в интересах отдельных индивидуумов неизбежно создают почву для конфликтов между ними. Добро и зло связаны между собой, поэтому у любых «идеальных» проектов, на которые так падки обычные люди, обязательно проявляются вредные (более-менее отдалённые) последствия - иногда гораздо более весомые, чем ожидавшиеся позитивные изменения. Отсутствие решений, полностью устраивающих все стороны, требует выработки и твёрдого соблюдения правил (законов), согласно которым должны вестись социальные взаимодействия. Бездарные и ленивые люди склонны к 
нарушению подобных правил, пытаясь присвоить не принадлежащие им блага с помощью обмана или грубой силы. Поэтому социальные пороки - в частности, войны, безработицу и преступность - никогда не удастся искоренить полностью.

К сожалению для любителей мечтать, уроки истории полностью противоречат утопизму: все попытки создания нового человека, живущего в идеальном обществе (например, в результате французской, российской «октябрьской» и китайской «культурной» революции) в итоге завершились своей противоположностью - большой трагедией - массовыми убийствами и деспотизмом правящей власти.

Исторические примеры появления «зла» из «добра» являются особенно показательными, поскольку зло возникает в результате следования именно утопическому подходу, декларирующему, казалось бы, наилучшие, самые добрые намерения. Истинность же трагического (точнее, теперь уже реалистического) взгляда, априорно не ожидающего от среднестатистического индивида ничего особенно выдающегося, подтверждается не только уроками истории, но и достижениями таких современных наук, как эволюционная биология и поведенческая генетика [22]. С нашей точки зрения, в этом нет ничего плохого: люди, осведомлённые о собственных, едва ли устранимых ограничениях и способности к созданию глобальных катастроф в результате погони за «немедленным добром», могут задуматься о том, чтобы стать скромнее в своих желаниях, терпимее и гуманнее друг к другу. Принятие и мудрое осмысление неучтённого заранее негатива, коррекция решений в пользу их большей взвешенности способны обернуться позитивом в долговременной перспективе. По крайней мере, крупных потрясений в этом случае человечеству удалось бы избежать.

И наоборот, утопические лозунги, основанные на показном гуманизме и навеянные позитивными иллюзиями, ведут к лицемерию (забвению истины), от которого недалеко и до реальной расправы с трезвомыслящими оппонентами. Так неистинное добро обретает своё настоящее обличье, становясь истинным злом, для которого хуже горькая правда, чем сладкая ложь.

К большому счастью, современных учёных, которые своими исследованиями показывают реальную (отнюдь не богоподобную) природу человека и состояние общества, не сжигают как в Средние века, однако по-прежнему готовы подвергнуть цензуре и остракизму - вплоть до увольнения со службы [11]. Сообщение дурных известий («недобрых истин», противоречащих позитивным иллюзиям масс) может привести к тому, что их носителю отсекут голову. Вспомним случай выдающегося психолога С. Милгрэма, отлучённого от работы в престижных университетах США после публикации результатов своего «обучающего» эксперимента, доказавшего способность абсолютного большинства испытуемых творить вовсе не добро, а какое угодно зло - вплоть до нанесения смертельных увечий ни в чём не повинному человеку [10].

Промежуточные выводы. Итак, свойственные человеку и усиливаемые современной цивилизацией позитивные иллюзии толкают его на непрерывные поиски добра («счастья»). В результате происходящее на бытовом уровне пренебрежение истиной (выявленными и подтверждёнными закономерностями) способствует развитию неадекватных представлений о том, что добро существует отдельно от зла; что добра в мире больше, чем зла; что добро обязательно победит, поскольку оно сильнее зла.

В противостоянии истины и добра позитивные иллюзии поддерживают добро двояким образом. Во-первых, они преувеличивают роль добра, поскольку являются позитивными. Вовторых, они преуменьшают роль истины, поскольку являются иллюзиями, заблуждениями.

Переоценка роли добра и его возможностей («так и должно быть») вызывает ускоренную адаптацию к нему. В то же время, в восприятии индивидом любых негативных явлений имеет место обратный процесс - повышение чувствительности, сенситизация («так быть не должно»). В результате зло субъективно оказывается сильнее добра, а современный человек получает полную противоположность тому, к чему он так стремился. Сложившийся 
когнитивный диссонанс между позитивными убеждениями и негативно воспринимаемым положением дел заставляет нетерпеливого индивида увеличить усилия в поиске доступного добра и в «борьбе» за него. Возникает порочный круг.

Добро: трудный выбор правильной последовательности. Переходя на иной, «метафизический» уровень рассуждений, мы будем временно обозначать истину, добро и зло с заглавных букв.

Итак, отвергнутая (пренебрегаемая Добром) Истина «мстит»: как только Добро побеждает Истину, Зло начинает побеждать Добро.

Добро, не опирающееся на Истину, непременно проиграет Злу, тем самым выдвинув его на первое место. Дело в том, что разновидности (как правило, краткосрочного) добра, впоследствии оборачивающиеся долговременным злом, являются яркими, привлекательными, сулящими лёгкое и быстрое наслаждение. Поэтому неосведомлённый о последствиях (не знающий горьких истин) человек с большой вероятностью выберет именно подобное «добро», за что потом будет долго расплачиваться. Заблуждающийся индивид не умеет отличать «правильное» Добро от «неправильного» и потому (при своём невысоком уровне развития и понимания) делает естественный для себя выбор в пользу «красивого», «быстрого», «приятного» - и очень вредного в перспективе. Даже искренне желая творить добро (себе и/или другим людям), он нередко творит зло: «благими намерениями вымощена дорога в ад».

И наоборот, если Истина (в качестве приоритетной ценности) ставится выше любого Добра, тогда «истинное» Добро имеет возможность одержать верх над Злом - во всяком случае, в своих долговременных последствиях.

Попутно отметим, что третья «вечная» ценность - Красота - зачастую становится на сторону неистинного добра, делая последнее более привлекательным, создавая, по выражению А. Шопенгауэра, наружную позолоту для пустых внутри орехов. Многие же открытые наукой истины, как смог убедиться читатель, «не блещут красотой», будучи похожими (согласно известной метафоре Марка Твена) скорее на тюленя, нежели на русалку.

Таким образом, человек, стремящийся творить добро, должен осознать, что Добро никогда не будет лидером в цепочке из трёх членов. Для Добра возможны две разумных последовательности, причём в обеих оно занимает лишь вторую позицию: «Истина-Добро-Зло» или «Зло-Добро-Истина» (любопытно, что вторая последовательность является перевёртышем первой). Добро, как мы убедились, не может выиграть «финальный поединок»; оно либо «покоряется» Истине в качестве приоритетной ценности, либо быстро уступает Злу, тем самым отодвигая Истину на третий план. Оснований для проигрыша Добра Злу (или превращения Добра в Зло) более чем достаточно (см. выше). Поэтому познание человеком истины и уважение к ней должны предшествовать попыткам «творения добра».

Вышеуказанное соображение, помимо прочего, ставит под сомнение результаты исследований современной позитивной психологии [12 и др.], не учитывающей взаимосвязь Добра и Зла, а потому разделяющей утопическое мировоззрение. По нашему мнению, односторонние («неистинные») рекомендации этой дисциплины не могут быть продуктивно использованы здоровым человеком; они способны помочь лишь индивидам с таким же «односторонним» сдвигом внутреннего равновесия в противоположную - негативную сторону вследствие имеющегося (как правило, депрессивного или тревожного) расстройства психики.

Возвращаемся к основной теме. Истина в принципе и не может занять вторую (после Добра) позицию, вклинившись в трёхчленную последовательность между Добром и Злом (либо между Злом и Добром), поскольку, как мы уже отмечали, Добро и Зло связаны между собой. Иными словами, даже опора на Истину не позволяет реализовать мечту утопистов - отыскать (либо сконструировать) абсолютное, «чистое добро», полностью отделить его от зла и благодаря этому поставить Добро впереди Истины. Если Истина располагается на второй позиции, значит, первый член последовательности автоматически освобождается от последующих «проверок на истинность», становясь открытым для любых искажений и 
злоупотреблений. Наши попытки в прошлом решить данную проблему позволили обнаружить один вид человеческой активности, лишь приближающийся к «истинному добру» по терминологическим, количественным и качественным критериям [6].

Как же Добро может сделать правильный выбор, предпочтя приоритет Истины перед самим собой? Ведь, как ни кощунственно звучит, выбор в пользу Зла Добру сделать легче, «натуральнее» по ряду причин.

Во-первых, Добро связано со Злом, хотя номинально является его противоположностью. И Добро и Зло эмоционально насыщены. В то же время Истина изначально не связана ни со Злом, ни с Добром - она существует сама по себе и не имеет отношения к «субъективным пристрастиям». Истина ни с кем и ни с чем не вступает в борьбу. Она просто существует, обретая «добрые» или «злые» трактовки в зависимости от эгоистических интересов людей, пытающихся использовать её для собственных нужд.

Типичным примером подобного использования выступают современные шахматы - вид деятельности, в котором компьютер оказался намного сильнее любого человека и, стало быть, гораздо ближе к пониманию шахматной «истины». В результате ухищрённые попытки использования компьютерных подсказок профессиональными шахматистами во время игры («читерство») приобрели характер эпидемии.

Во-вторых, большинство открытых истин не являются «добрыми», приятными для восприятия. Наоборот, они скорее «неприятны» для простого человека по своему содержанию и возможным выводам. Кого, например, может обнадёжить факт, что в мире так и не обнаружен «высший замысел» или хотя бы некий внешний источник смысла, способный придать более твёрдые основания существованию индивида? Наоборот, отмечает Нобелевский лауреат С. Вайнберг, чем лучше учёные познают мир, тем более бессмысленным он им кажется [3]. Как пишет Р. Триверс, одним из самых распространённых является заблуждение, согласно которому жизнь естественным образом эволюционирует так, чтобы удовлетворить потребности единиц более высокого уровня [13, с. 401-402].

Может сложиться впечатление, что открытые истины, наоборот, увеличивают количество Зла в мире - как по своему «неоптимистическому» содержанию, так и вследствие попыток некорректного (чересчур прямолинейного) их использования. Учёные не нашли «чудесное», зато постоянно обнаруживают нечто подозрительное и малоприятное. Парадоксально, что надежда человека на «лучшее» нередко сохраняется там, где наука «недорабатывает». Например, доказательства существования бога не обнаружены, однако доказать его отсутствие также пока не представляется возможным - бальзам на душу верующих людей.

Как следствие, обычному человеку может казаться невыгодным поиск истины и пребывание в контакте с ней. Мало того, что его собственный, «природный» оптимизм способен уменьшиться, так ухудшаются и отношения с другими людьми, которые не желают слушать «негатив» о себе и окружающем мире: «много знания несёт много печали». Плохое отношение к средневековым учёным (Бруно, Галилей, Коперник), а также их более современным последователям (Дарвин, Фрейд) было связано, в первую очередь, с тем, что совершённые ими открытия противоречили позитивно-иллюзорным представлениям людей о собственном богоподобии и особом положении человечества во Вселенной [7].

Обычный индивид, находящийся под воздействием манипуляторов, далеко не всегда стремится к их разоблачению - до тех пор, пока слышит из их уст «сладкую ложь». И в самом деле: почему бы не дополнить приятный внутренний самообман обманом внешним? Ведь разоблачение и исчезновение внешнего «очаровывателя» неизбежно оставляет человека наедине с самим собой и неумением организовать собственную жизнь за счёт прилагаемых систематических усилий. Именно поэтому многие люди склонны сердиться, когда им напоминают реальное, отнюдь не радостное положение дел. Парадоксально, что при этом они вовсе не ставят под сомнение истинность (правдивость) того, что им сообщается. Так 
позитивные иллюзии борются с неудобными для них фактами ради хорошего самочувствия и поддержания самооценки индивида.

Именно потому, что открытая учёными истина доказательным образом разбивает позитивные иллюзии (конечно, не потому, что они позитивные, а потому, что они противоречат выявленным закономерностям), и тем самым как бы уменьшает основания для надежды, складывается поверхностное впечатление, что Истина располагается ближе к Злу, нежели к Добру. От соприкосновения с Истиной многие разновидности Добра либо «слабеют», сходят на нет (например, в связи с выявленным феноменом адаптации), либо, что ещё хуже, демонстрирую свою «злую» сторону - как, например, в случае аддикций. На самом деле ближе к Злу находится не Истина, а Добро - по крайней мере, многие его «неистинные» разновидности. Истина же просто фиксирует существующее положение вещей.

Полная «победа» Истины над Добром означала бы необходимость отказа от большей доли позитивных иллюзий, питающих надежды, оптимизм и самооценку человека. Однако подобный отказ не только неприятен субъективно, но и вряд ли полностью возможен. Ведь позитивные иллюзии рождаются на глубинных, неосознаваемых уровнях функционирования мозга, а потому не находятся под прямым контролем субъекта. Также не каждый готов делать постоянные мысленные поправки на возможную собственную необъективность и всё время сверяться с реальностью.

С другой стороны, простое знание о собственной уязвимости в данном аспекте например, склонности верить ярким и привлекательным обещаниям - способно принести человеку пользу, особенно в долговременной перспективе. Нет смысла проводить время в борьбе с позитивными иллюзиями (они осуществляют и полезные функции; полностью победить их не удастся), но полезно быть осведомлённым об их действии и потому проявлять большее внимание к фактам в ситуации важного выбора.

Может быть, и к сожалению, что современной нейронаукой не обнаружены противоположные - негативные иллюзии, которые были бы столь же широко свойственны человеческому мозгу и которые истина могла бы развеять, тем самым доказав свою способность не только снижать, но и повышать уровень субъективного благополучия, вселять обоснованную надежду. Заблуждения и сопутствующий пессимизм индивида при наличии у него депрессивного или тревожного расстройства нами не рассматриваются, поскольку статистической нормой (пока, во всяком случае) не являются.

Таким образом, Добро обязано признать приоритет Истины над самим собой - хотя бы в целях подавления Зла, его сдвига на последнюю, третью позицию. Добро «должно быть с кулаками» по отношению к Злу, но не к Истине. Как же осуществить подобную, не слишком приятную, однако трудную и необходимую операцию?

Для успешного принятия Истины в качестве приоритетной ценности индивиду полезно хорошо представлять её преимущества в сравнении с Добром. Во-первых, приверженность Истине делает для человека явной, более «осязаемой» связь многих видов «добра» с последующим злом. Так, известный биолог Р. Триверс прямо пишет, что, наученный опытом, взял за правило не идти после вечеринки в постель с малознакомой партнёршей, чтобы не испытывать в последующем неприятных чувств вины и тревоги [13]. Таким образом, знание истины (реального положения дел и наиболее вероятных - в том числе, негативных последствий) предостерегает человека от внешне привлекательных, но потенциально опасных видов деятельности, вред от которых несравним с коротким гедонистическим удовольствием. Во-вторых, Истина демонстрирует недолговечность, быстрое «затухание» приятных ощущений от получения многих видов Добра вследствие адаптации к ним. Наконец, в третьих, Истина указывает на долговременное, («настоящее», «истинное») Добро, нередко требующее приложения первоначальных усилий, однако приносящее радость в течение длительного времени и оборачивающееся многими полезными эффектами. Подобные виды Добра не 
«блекнут» подобно цветам-однодневкам, а становятся лишь сильнее от взаимодействия с Истиной.

Таким образом, Истина не губит Добро - она лишь распознаёт степень истинности того или иного добра и, подобно бритве, отрезает многие виды «ложного» добра, процветающего за счёт человеческой алчности, недальновидности и позитивных иллюзий. Разумеется, мы не предлагаем отказываться от Добра как ценности. Ведь эвдемония - достижение субъектом жизненной гармонии [5] - предполагает следование не только Истине (хотя вначале именно ей), но также ценностям Добра и Красоты [20]. Именно в контексте сказанного уместна мысль Г. А. Балла, согласно которой добро в конечном итоге побеждает зло, поскольку опирается на «сущностные закономерности бытия» [1] - ту же Истину.

Итак, в последовательности «Истина-Добро-Красота» добро уменьшается количественно, зато прибавляет в качестве, становясь тем добром, «которому можно доверять», которое действует благоприятным для человека образом в течение долгого времени и при этом не обладает заметными негативными эффектами. Длительное воздействие добра, его неподверженность «конъюнктуре» и сиюминутным эмоциям как раз и служит доказательством его близости к истине (поскольку истина, как мы знаем, вечна и «независима»). А тот факт, что долгосрочное добро «высвобождается» понемногу, может служить определённой гарантией, что сопутствующее многим видам добра зло в данном случае практически отсутствует. Единственным условным (для ленивого индивида) «злом» могла бы служить необходимость приложения каждодневных усилий при освоении полезных видов активности. Что ж, в подобном случае гедонисту полезно представлять разные (не только иллюзорно-позитивные) варианты своего будущего. Так или иначе, саморазвитие требует периодического выхода субъекта из зоны комфорта - ради большего благополучия в будущем.

И наоборот: если индивиду сулят сразу много хорошего, то ему очень полезно остановиться (в своих позитивных иллюзиях) и задуматься, не становится ли он объектом очередной манипуляции, и какое долговременное зло может караулить его в недалёком будущем. Как известно, бесплатный сыр («краткосрочное добро») бывает только в мышеловке («пожизненное зло»). Увы, далеко не все люди вспоминают данную истину, когда оказываются в ситуации искушения.

Примером вышесказанному могут служить результаты сравнительного анализа эффективности разных методов психотерапии. Так, принимаемые пациентом лекарства действуют достаточно быстро на симптомы расстройства и просты в употреблении («быстрое и лёгкое добро»), в то время как немедикаментозные методы (разговорные методики, упражнения по релаксации, поведенческие задания) действуют не сразу и поначалу требуют приложения усилий. Однако именно в долгосрочной перспективе выявляются нарастающие минусы лекарственной терапии: ослабление действия медикаментов, неспособность пациента жить без них («лекарственная наркомания»), нарастающие побочные (токсические) эффекты, потеря пациентом умения самостоятельно (за счёт личных усилий) справляться с аналогичными трудностями в будущем. По контрасту, действие правильно организованных и ежедневно практикуемых немедикаментозных приёмов кажется поначалу скромнее. Однако они не дают вредных для здоровья осложнений, прививают полезные привычки, дают нарастающий позитивный эффект с увеличением времени, учат пациента активно и самостоятельно преодолевать трудности - сейчас и в будущем.

Когда медицина станет мудрее, она, помимо борьбы со «злом» (симптомами болезни), сосредоточит свои усилия на противодействии «неистинному добру» - всевозможным быстрым наслаждениям, в больших количествах порождающим аддикции и, в перспективе, серьёзные заболевания. Критически важно разоблачать зло (в основном, в качестве грядущих негативных последствий) на самой ранней стадии - ещё тогда, когда оно кажется лёгким и привлекательным добром. 
Автор статьи был бы счастлив, если позитивные иллюзии индивида смогли бы поддерживать и усиливать долгосрочные разновидности добра, опирающегося на уже открытые истины. К сожалению, чаще имеет место обратное. Привычка получать быстрые и лёгкие наслаждения, не задумываясь о долговременных (негативных) последствиях, вошла в плоть и кровь современного «рыночного» человека. Невозможно одним росчерком пера повернуть потребительски ориентированное общество в правильном направлении - во всяком случае, до тех пор, пока сопутствующие «цветы зла» не станут актуальными для каждого безудержного гедониста.

Тем не менее, вдумчивый индивид способен обнаружить отнюдь не иллюзорный повод для оптимизма (надежды) практически в любой достоверной («истинной») информации. Так, упомянутое выше отсутствие «внешнего» смысла («сверхзамысла») означает свободу индивида в его создании лично для себя. Феномен быстрого привыкания к гедонистическим удовольствиям позволяет больше ценить первые мгновения наслаждений, стараясь в целом делать их реже, но разнообразнее. Необходимость приложения усилий для освоения более сложных видов деятельности, устойчивых к адаптации, подразумевает полезность пребывания индивида в общем тонусе, важном для долгой и продуктивной жизни. Таким образом, истинная позитивная жизненная философия не является «простой и первичной», изначально данной: она способна возникнуть на основе творческого осмысления, субъективной «обработки» проверенных данных, поскольку последние содержат в себе не только «чистый и безусловный» позитив. Легко убедиться, что сказанное лишний раз доказывает приоритет Истины перед Добром: Истина уже существует, в то время как «правильное» Добро на её основе ещё нужно создать.

Проблема для власти: неприятие массами истины, адаптация к добру. Проследим вышесказанное на конкретном примере, касающимся взаимодействия власти с выбравшим её народом. По нашему мнению, мудрая власть должна говорить с народом на «языке добра», однако опираться на истину (информированность и учёт всех основных факторов) в реально предпринимаемых шагах. К сожалению, истина такова, что в большой политике неизбежна доля лицемерия.

Власть не может открыть народу все «недобрые истины» о положении государства, поскольку в этом случае её престиж в глазах масс непоправимо упадёт. Власть, вероятно, знает о подверженности людей позитивным иллюзиям, поэтому периодически стремится давать обещания (иногда откровенно утопические), создавая временные поводы для оптимизма экономические (каждому работающему среднюю зарплату в пятьсот долларов), политические (вся власть Советам; вперёд к победе коммунизма) или бытовые (каждой женщине по мужчине). Также власть, вероятно, понимает, что успешное выполнение каждого из обещаний не слишком для неё полезно: оно быстро создаст адаптацию масс к полученному благу, и люди вскоре захотят ещё большего (так будет продолжаться до бесконечности).

Многие невыполненные обещания впоследствии можно объяснить внешними причинами (неурожайный год, происки Запада) и заменить их другими замечательными проектами, поскольку предвкушение добра, как читатель уже знает, не менее приятно для людей, чем само добро.

Также надо понимать, что интересы госчиновников лишь частично соприкасаются с интересами народа. Главным для власти является самосохранение. Для масс же установление новой власти нередко сопровождается бурной радостью (позитивные иллюзии, предвкушение добра), сменяемой усталостью и недовольством вследствие неизбежной адаптации и невыполнения властью большинства обещаний. И так в каждом новом цикле.

Практические советы по самоорганизации. Ниже мы дадим полезные рекомендации тем немногим людям, которые уже сегодня склонны выбирать надёжный, хотя и не всегда радостный путь приоритетного следования истине, а не сомнительному краткосрочному 
«добру». В качестве вступления приведём красноречивые результаты одного лонгитюдного исследования.

Экспериментатор предлагал маленьким детям (4-6 лет) дилемму: скушать сразу одну вкусную конфету (краткосрочный гедонизм) или потерпеть несколько минут, после чего скушать две. Затем взрослый временно покидал комнату, оставляя ребёнка наедине с лакомством. Те дети, которые смогли отсрочить получение удовольствия (от 10 до 30 проентов в разных выборках), впоследствии, как выяснилось, гораздо лучше учились в школе в сравнении с «нетерпеливыми» сверстниками-гедонистами, а также больше преуспели во взрослые годы. В целом их жизнь складывалась благополучнее во многих отношениях [4].

Приводимые ниже рассуждения, обобщающие всё вышесказанное, ведутся от первого лица - для того, чтобы любой (отныне информированный) человек мог бы освоить их в качестве практических приёмов собственного мышления - «правильного разговора с самим собой». Итак.

«Я хотел бы прожить долгую и по возможности счастливую жизнь. Теперь мне известно о внутренней склонности человека к получению быстрых наслаждений, которая может помешать мне в дальнейшем. Также я знаю о наличии у каждого индивида позитивных иллюзий, которые иногда полезны, а иногда нет. Если я собираюсь опираться на истину в качестве приоритетной ценности, мне следует признать имеющиеся у меня склонности, свойственные не только людям, но и всем живым организмам. Осведомлённость о подобных ограничениях позволит мне лучше их контролировать - разумным и умеренным образом наслаждаясь жизнью, по возможности избегая привыкания благодаря нечастому использованию одних и тех же удовольствий и не впадая в зависимость от них. Понимание и принятие собственных (равно как и общечеловеческих) ограничений не означает невозможности для меня уменьшить их влияние благодаря разуму, способностям и трудолюбию. Наоборот, теперь я лучше понимаю, на чём именно следует сосредоточить усилия, чтобы прожить собственную жизнь.

Чисто внешне моё существование не покажется чересчур ярким, однако я уверен, что нахожусь на правильной («истинной») стороне бытия и смогу, помимо прочего, избежать многих несчастий и стрессов, с которыми, вероятнее всего, столкнутся другие люди. Теперь я лучше вижу отдалённые последствия (глубинную суть) своих решений и потому способен отличить «истинное» добро от «неистинного», стараясь делать выбор в пользу первого. Поэтому я не стану жертвой распространённых манипуляций, но и не буду манипулировать окружающими, поскольку честность (справедливость, следование истине) - наиболее приемлемый для меня образ жизни.

Также мне известно о существовании занятий (видов деятельности), которые практически не вызывают вредных эффектов. Наоборот, они способны дарить много приятных и полезных, уникальных переживаний в течение длительного времени, тем самым развивая человека в любом возрасте. Психологи считают вовлечённость в подобные виды деятельности наивысшим счастьем, которое возможно для человека. Многие люди не хотят их осваивать, так как не желают прилагать серьёзные усилия в первоначальный, наиболее трудный период обучения. Я не стану повторять дурные примеры, даже если они носят массовый характер. Мне известно, что получение истинного и долговременного жизненного позитива почти всегда требует первоначального выхода из зоны комфорта и некоторого самопреодоления. Я буду стараться регулярно делать это ради множества полезных и приятных последующих переживаний, для саморазвития и осмысленной жизни. Поэтому я составлю примерный список таких видов активности и начну их практиковать, пока не найду «своё» - занятие, которое отвечает моим внутренним особенностям и позволит в будущем в наибольшей степени реализовать собственные возможности.

На этом пути я не стану избегать и негативных переживаний, если они будут неизбежны, поскольку такие эмоции имеют и полезные функции, своевременно предупреждая о возможных 
угрозах и держа психику в тонусе. Осведомлённость о многих трагических сторонах человеческого существования в целом не вызывает у меня пассивности и отчаяния, не лишает оптимизма. Наоборот, подобные знания мобилизуют; они заставляют ещё сильнее ценить позитив, который я достигаю собственными усилиями.

В целом я надеюсь, что культивирование всех названных привычек позволит мне прожить уникальную, насыщенную и творческую жизнь, которая недоступна для людей, одержимых позитивными иллюзиями и гоняющихся за быстрыми удовольствиями».

Личный onыm aвmopa. Советы о том, как следует жить другим людям, могут приниматься к сведению лишь в случае их личной проверки автором. Именно поэтому я решил добавить данный раздел в нынешнюю статью. В своём кратком отчёте я перехожу к описаниям от первого лица, чтобы подчеркнуть личную ответственность за сказанное. Подобная нескромность является для меня вынужденной - в обычной повседневной жизни я считаю для себя более полезным не выделяться.

Мне повезло в том смысле, что специфика научной работы «по умолчанию» нацеливает на поиск истины. Однако психология по-прежнему не дотягивает до статуса полноценной научной дисциплины. Неясность в определении центрального понятия (что такое душа, психика?), открытость любым веяниям ведёт к созданию множества не связанных между собой псевдонаучных теорий, во многом отражающих не «истину», а личные пристрастия того или иного автора (его представления о добре, зле или красоте). Такая «наука» неизбежно превращается в идеологию, начиная обслуживать эгоистические интересы определённых групп людей и крупных (в том числе, государственных) структур. Конечно, искать решение жизненно важных, ценностно-смысловых вопросов в открытой всем ветрам дисциплине было для меня невозможным.

Поиски и размышления о том, что является истиной (или, по крайней мере, приближением к ней) в результатах исследований, полученных разными науками о человеке, создали у меня уверенность в том, что базовым, центральным понятием для психологии должен стать эгоизм, понимаемый как врождённая предрасположенность человека в свою пользу, забота о собственных интересах. Соответственно, разработанная мной многоуровневая модель («Личностно-ориентированная концепция счастья» - ЛОКС), в которой эгоизм выступает в качестве одной из двух конституирующих систем, предлагается на роль «окончательной» теории для психологической науки, тем самым давая последней множество преимуществ, позволяя непротиворечивым образом встроиться в современную научную иерархию «биопсихо-социо». Подобная операция подразумевает и смену названия психологии на эгологию науку, изучающую, в первую очередь, потребности, мотивацию, интересы и желания индивидов, а также возможности их продуктивной реализации.

Конечно, соотношение Истины, Добра и Зла в рамках «эгологических» исследований имеет для меня громадный интерес - ещё и потому, что человеческий эгоизм представляет собой желание добра своему носителю (это установленная истина). Разумеется, мне самому не чужд эгоизм в различных формах, поэтому я всегда понимаю, о чём говорю и что исследую.

Теперь я ощущаю, что главные, «экзистенциальные» вопросы в моём существовании оказались успешно решены - вместе с научной темой я «нашёл настоящего себя». Занятие делом по призванию создало в последние годы немыслимую ранее продуктивность, привело к сотням публикаций, быстрому написанию и защите докторской диссертации. Я отлично понимаю свои истинные цели, «миссию» и судьбу. Соответственно, многие распространённые жизненные неприятности и стрессы обходят меня стороной, поскольку вовремя распознаются и не имеют почвы для укоренения. Так служение Истине приносит долговременное Добро и одновременно позволяет избежать многих разновидностей Зла.

Предвосхищу вопрос читателя: каждый ли сможет «найти себя», развить и реализовать свой «уникальный творческий потенциал»? Честный ответ: не уверен. Выше говорилось о том, что, вероятнее всего, врождённым «талантом» обладают лишь немногие люди. У меня самого 
подобный «взлёт» случился уже после 50 лет. До этого я перепробовал множество занятий (шахматы, альпинизм, спортивное скалолазание и т. д.), однако всюду лишь слегка приподнимался над средним уровнем, хотя много и упорно тренировался.

Впрочем, для меня очевидно и другое: если каждый индивид будет искать и пробовать, прилагать усилия по саморазвитию, тогда число обнаруженных и раскрывшихся талантов будет неизмеримо выше нынешнего.

Формула мудрости. Со времён античности существует известное многим представление о том, как следует жить мудрому человеку. Он должен стремиться улучшить то, что в его силах, принимать то, что он изменить не в состоянии, и уметь отличать первое от второго.

В свете проделанного нами анализа формула мудрой жизни наполняется более конкретным содержанием. Информированный субъект отныне должен: а) понимать глубинную взаимосвязь добра и зла, принимать вытекающие из этого различия в интересах (эгоизме) конкретных индивидов; б) уметь различать краткосрочные (как правило, гедонистически ориентированные) и долговременные разновидности добра, в разной степени опирающиеся на истину, и потому имеющие разную степень связи со злом; в) направлять свои усилия и мотивацию на контакт и культивирование долгосрочных форм добра, предохраняющих от многих жизненных неприятностей, способствующих саморазвитию, самореализации и устойчивому чувству благополучия.

1. Балл, Г. А. (2009). К проблеме взаимосвязи добра и зла в социальном поведении. Журнал практикующего психолога, 15, 141-156.

2. Брафман, О., Брафман, Р. (2009). Шпаргалка для счастливчика. М.: АСТ.

3. Вайнберг, С. (2004). Мечты об окончательной теории. М.: Едиториал УРСС.

4. Зефирный эксперимент (2018). Взято из https://ru.wikipedia.org/wiki /Зефирный_эксперимент.

5. Левит, Л. 3. (2014). Личностно-ориентированная концепция счастья: эвдемония и уровни удовольствия. Научный журнал «Eduсаtio», 4 (5), 34-37.

6. Левит, Л. 3. (2017). Истинное добро: суперценность и её критерии. Теория и практика культурноисторической психологии. Материаль ХҮІІ Международных чтений памяти Л.С. Выготского, 260-269.

7. Левит, Л. 3. (2017). Научные открытия как удары по самолюбию: традиция продолжается. Психологія особистості, 1 (8), 67-77.

8. Левит, Л. З., Радчикова, Н. П. (2013). Опросник ЭЛУ: в борьбе с правосторонней асимметрией. Электронный научный журнал «Исследовано в России», 017, 244-261.

9. Любомирски, С. (2014). Психология счастья. СПб.: Питер.

10. Милгрэм, С. (2017). Подчинение авторитету. М.: Альпина нон-фикшн.

11. Научный скандал года: учёные писали фейк-исследования, чтобы разоблачить лженауку. (2018). Взято из http: news.tut.by/world/610477.html.

12. Селигман, М. (2006). Новая позитивная психология. Киев: София.

13. Триверс, Р. (2012). Обмани себя. СПб.: Питер.

14. Ялом, И. (1999). Экзистенциальная психотерапия. М.: НФ «Класс».

15. Compton, W.C. (1992). Are positive illusions necessary for self-esteem: a research note. Person. Individ. Dif, Vol. 13 (12), 1343-1344.

16. Diener, E., Biswas-Diener, R. (2008). Happiness. Blackwell Publishing.

17. Forest, J. J., Sicz, G. (1981). Pseudo-self-actualization. Journal of Humanistic Psychology, Vol. 21 (1), 77-83.

18. Frick, W. B. (2000). Remembering Maslow: Reflections on a 1968 interview. Journal of Humanistic Psychology, V. 40 (2), 128-147.

19. Goethals, G. R., Messick, D.M., Allison, S.T. (1991). The uniqueness bias: Stidies of constructive social comparison. Social comparison: Contemporary theory and research, 149-176.

20. Lane, T. J., Flanagan, O. (2013). Neuroexistentialism, eudaimonics, and positive illusions. Mind and Society: Cognitive Science Meets the Philosophy of the Social Sciences, 1-28.

21. Myers, D. (2002). The Pursuit of Happiness. New York: Quill.

22. Pinker, S. (2002). The Blank Slate. New York: Penguin Books.

23. Veenhoven, R. (2003). Hedonism and happiness. Journal of Happiness Studies, Vol. 4, 437-457.

\section{REFERENCES}

1. Ball, G. A. (2009). K probleme vzaimosvjazi dobra I zla v socialnom povedenii [The problem of a connection between good and evil in social behavior]. Zhurnal praktikujushego psihologa [The Journal of a Practicing Psychologist], $15,141-156$. (rus). 
2. Brafman, O., Brafman, R. (2009). Shpargalka dlja shastlivchika [A crib for a lucky man]. M.: AST. (rus).

3. Wainberg, S. (2004). Mechty ob okonchatelnoj teorii [Dreams of a final theory]. M.: Editorial URSS. (rus).

4. Zefirnyi eksperiment [The marshmallow experiment]. (2018). Retrieved from https://ru.wikipedia. org/wiki /(zefirnyi eksperiment). (rus).

5. Levit, L. Z. (2014). Lichnostno-orientirovannaja koncepcija schastja: evdemonija i urovni udovolstvija [Personoriented Conception of Happiness: eudaimonia and levels of pleasure]. Nauchni zhurnal "Educatio" ["Educatio" journal], 4(5), 34-37. (rus).

6. Levit, L. Z. (2017). Istinnoje dobro: supertsennost I ee kriterii [True good: the supervalue and its criteria]. Teorija I praktika kulturno-istoricheskoj psihologii. Materialy XYIII Mezhdunarodnih chtenij pamiati L.S. Vygotskogo [Theory and practice of cultural-historical pdychology. The materials of the XYIII International readings in memory of L.S. Vygotsky], 260-269. (rus).

7. Levit, L. Z. (2017). Nauchnije otkrytija kak udari po samoljubiju: traditsija prodolzhaetsja [Scientific discoveries as the blows to self-esteem: the tradition continues]. Psihologija osobistosti [Psychology of personality], 1 (8), 6777. (rus).

8. Levit, L. Z., Radchikova, N.P. (2013). Oprosnik ELU: v borbe s pravostoronnej asimmetrijej [The ELU questionnaire: fighting the right-side asymmetry]. Elektronni nauchni zhurnal «Issledovano v Rossii» [Electronic scientific journal «Explored in Russia»], 017, 244-261. (rus).

9. Lubomirski, S. (2014). Psihologija shastja [The psychology of happiness]. Spb.: Piter. (rus).

10. Milgram, S. (2017). Podchinenije avtoritetu [Submission to the authority]. M.: Alpina-non-fiction. (rus).

11. Nauchni scandal goda: uchenyje pisali feik-issledovanija, chtoby razoblachyt lzhenauku [Scientific scandal of the year: the scientists wrote about fake explorations in order to disclose fake science]. (2018). Retrieved from https:// news.tut.by/world/610477.html. (rus).

12. Seligman, M. (2006). Novaja positivnaja psihologija [New positive psychology]. K.: Sofija. (rus).

13. Trivers, R. (2012). Obmani sebja [Deceive yourself]. Spb.: Piter. (rus).

14. Yalom, I. (1999). Ekzistentsialnaja psihoterapija [Existential psychotherapy]. M.: Class. (rus).

15. Compton, W. C. (1992). Are positive illusions necessary for self-esteem: a research note . Person. Individ. Dif., V. 13, 12, 1343-1344.

16. Diener, E., Biswas-Diener, R. (2008). Happiness. Blackwell Publishing.

17. Forest, J. J., Sicz, G. (1981). Pseudo-self-actualization. Journal of Humanistic Psychology, V. 21, 1, 77-83.

18. Frick, W. B. (2000). Remembering Maslow: Reflections on a 1968 interview. Journal of Humanistic Psychology, V. 40, 2, 128-147.

19. Goethals, G. R., Messick, D. M.\& Allison, S. T. (1991). The uniqueness bias: Stidies of constructive social comparison. Social comparison: Contemporary theory and research, 149-176.

20. Lane, T. J., Flanagan, O. (2013). Neuroexistentialism, eudaimonics, and positive illusions. Mind and Society: Cognitive Science Meets the Philosophy of the Social Sciences, 1-28.

21. Myers, D. (2002). The Pursuit of Happiness. New York: Quill.

22. Pinker, S. (2002). The Blank Slate. New York: Penguin Books.

23. Veenhoven, R. (2003). Hedonism and happiness. Journal of Happiness Studies, Vol. 4, 437-457.

\section{Leonid Levit \\ THE EVIL IS STRONGER THAN THE GOOD IF THE GOOD IS MORE IMPORTANT THAN THE TRUTH: THE PROOFS AND THE CONSEQUENCES}

The article investigates the ratio between the main three human values - the truth, the good and the beauty. The analysis of the well-known philosophical postulates is conducted with the help of the results obtained in modern experimental researches. In particular, the author discusses the contradiction between the demand of the truth priority if the latter gets in conflict with the good, and the influence of the positive illusions, discovered by modern neuroscience and peculiar to human brain functioning. Thus the wide-spread effect of false uniqueness makes a person to overestimate her own (in fact highly wished) positive traits of character and underestimate negative ones. Mass proneness to the beliefs about individual inner potential and deeply seated resources combined with the desire of high self-esteem lead to the wrong social comparisons. The author of the paper proves that the priority of the good in comparison with the truth inevitably causes the situation, in which the evil defeats the good. This occurs because the untrue good is more easily achieved and utilized than the true good. On the contrary, the main advantage of the priority of the truth is the ability to discern and make distinctions between long-term forms of the good and its short-term (as a rule, hedonistically oriented) variants, which often turn to evil in the future perspective. As a rule, the genuine (true) good demands some efforts from an individual at first, but brings benefits and numerous useful effects for much longer periods of time. At the end of the paper, the author gives practical recommendations and shares his personal experience, which can help the informed individual to organize his own thinking and behavior with the help of the discovered regularities.

Keywords: adaptation, good, evil, truth, positive illusions, meaning, egoism. 